\title{
Influence of adult courtship experience on the development of sexual preferences in zebra finch males*
}

\author{
KLAUS IMMELMANN, RAGNA PRÖVE, REINHARD LASSEK \& \\ HANS-JOACHIM BISCHOF† \\ Lehrstuhl Verhaltensphysiologie, Fakultät Biologie, Universität Bielefeld, Postfach 8640,4800 Bielefeld 1, \\ Germany
}

(Received 29 May 1990; initial acceptance 15 July 1990;

final acceptance 23 November 1990; MS. number: 3587)

\begin{abstract}
Young zebra finch, Taeniopygia guttata castanotis, males were raised by Bengalese finch, Lonchura striata, foster parents until day 35,40 or 50 of age, respectively. Following isolation until day 100 , about half of the birds in each age group were tested for their preference for Bengalese or zebra finch females in two double-choice tests (pretests). After breeding experience with a conspecific female for 7 months, their sexual preferences were re-tested in two series of five double-choice tests (post-tests), one series 14 days after breeding experience, the other 7-12 months later. Preferences established during early development were changed by breeding experience. However, this change in preference was suppressed by preceding short phases of courtship experience with the foster parent species (during the pretests) after isolation. The same results were obtained by double-choice tests on the same birds 7-12 months later, demonstrating that the acquired preferences are quite stable. Large individual differences in the preferences of the birds may be caused by as yet unknown, subtle differences in rearing conditions. It is proposed that the preferences acquired during early development have to be stabilized by courtship experience. If the adequate object for courting is replaced by another one, a new preference may emerge. The extremely short time which is needed for consolidation may be explained by the high arousal level during pretests.
\end{abstract}

Imprinting is a learning process which has been characterized by two main features, namely that learning is restricted to a sensitive phase, and that the preference for the parental species which is acquired during this sensitive phase is remarkably stable (Immelmann \& Suomi 1981). One of the most extensively studied examples is sexual imprinting in the zebra finch, Taeniopygia guttata (see review in Immelmann 1985; Kruijt 1985). Whereas it was initially thought that the time course of the sensitive phase for sexual imprinting is relatively short and fixed (e.g. Immelmann 1972), further research has demonstrated that the duration of the sensitive phase is very flexible and

\footnotetext{
*This study was started in 1980 and was completed in 1986. In October 1988, J. Kruijt and his colleagues, who had been doing similar experiments independently, learnt that we were analysing Immelmann's unpublished findings. We agreed to publish our results simultaneously.

†To whom all correspondence should be addressed.
}

depends substantially on the experimental design (Bateson 1981). For example, zebra finch males that were raised by their own parents became imprinted earlier than those that were raised by a foster species, the Bengalese finch, Lonchura striata (Immelmann 1972; Immelmann \& Suomi 1981). When young birds were raised by Bengalese finch foster parents and were then given social contact with several conspecific males and females for 60 days, a shift in preference was possible even in birds that had been housed with their foster parents for, in two extreme cases, 57 and 71 days, respectively (Immelmann \& Suomi 1981; Immelmann 1985). However, Immelmann (1972, 1985) suspected that additional experience after 100 days of age would not change preferences that were acquired during development, since male zebra finches, which had become imprinted on Bengalese finches, retained their preference for the foster-species, even if they had had months of contact and even breeding experience with conspecific females after 100 days of age (Immelmann 1972, 1985). 


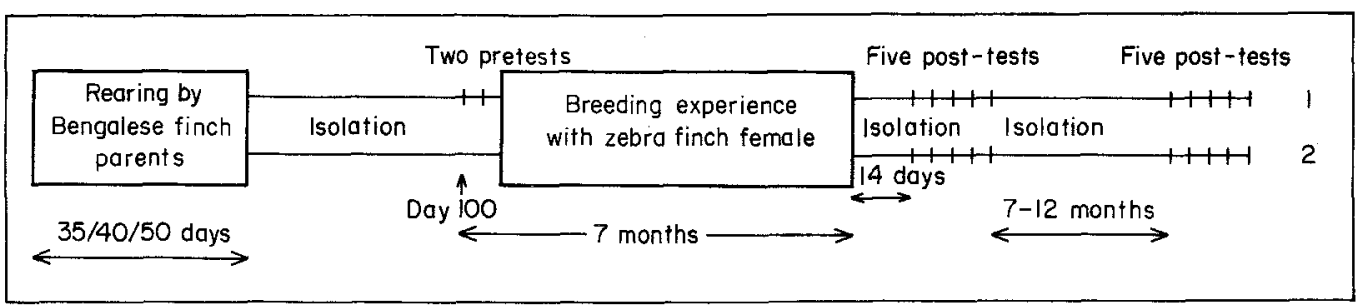

Figure 1. Outline of the experimental design. 1: group 1, with pretest, 2: group 2, without pretest. For further explanations see text.

Some preliminary observations, however, cast doubts on this conclusion (K. Immelmann, personal communication, cited in Bischof 1979): under certain circumstances breeding experience beyond 100 days of age could change the initial preference of cross-fostered zebra finches. These preliminary observations further suggest that a double-choice test at 100 days of age, just before the breeding experience began, was essential for retaining the initial preference. The present experiments were performed to elucidate further the role of secondary experience on the development of stable sexual preferences in male zebra finches. If this secondary experience is necessary for the consolidation of sexual preferences, current views on the mechanism of imprinting may require revision (see also Kruijt \& Meeuwissen 1991).

\section{METHODS}

The experimental design is shown in Fig. 1. Eggs from zebra finch parents were transferred to Bengalese finch pairs that were at about the same phase of the breeding cycle. After hatching, the young birds stayed with their foster parents for 35,40 , or 50 days. The number of siblings varied between two and four. Males were then individually isolated in cages where they could hear but not see conspecifics.

At 100 days of age, about half of the birds (the exact number of birds in each experiment is indicated in Figs 2 and 3) in each group were tested in two double-choice tests (pretests) with a Bengalese and a zebra finch female (both reared by conspecific parents and unknown to the experimental bird). Each test lasted $20 \mathrm{~min}$. Between the tests the birds were isolated for 2 days. Thereafter, the birds were put in a breeding cage together with a zebra finch female for 7 months. In all cases, the birds formed pairs and eventually reared several clutches of young. The other males of each age group were put in a breeding cage together with a zebra finch female at 100 days of age, directly after isolation (i.e. without pretests).

At the end of the 7 months the males were isolated for another 14 days. Then, all males were tested in a series of five double choice tests (posttests first series), where the birds could again choose between Bengalese and zebra finch females. Between the tests, the birds were isolated for 3 days.

Another series of double-choice tests was performed 7-12 months later. The birds were isolated again between tests.

The pre- and post-mate choice tests were performed in a cage divided into three compartments, the two outer compartments $(30 \times 40 \times 40 \mathrm{~cm})$ housing the zebra finch and Bengalese finch female, respectively. The test male was put into the central compartment $(60 \times 40 \times 40 \mathrm{~cm})$ for $20 \mathrm{~min}$, and the number of song phrases directed to each female was counted (for details see Immelmann 1959). The usefulness of this test design for measuring sexual preferences as a predictor for pair formation has been confirmed by ten Cate (1985). From the original values obtained during these tests, a preference score (PS) was calculated according to a formula similar to that used by Kruijt et al. (1983)

$$
\mathrm{PS}=\frac{Z}{B+Z} \times 100
$$

where $Z=$ number of song phrases directed to the zebra finch female and $B=$ number of song phrases directed to the Bengalese finch female.

If a test bird shows an exclusive preference for Bengalese finch females the score is zero, whereas if the male sings only to zebra finch females the score would be 100 . A score of 50 thus means that the male directed an equal number of song phrases to both females. The means of the preference scores from the two pretests and the five post-tests, 


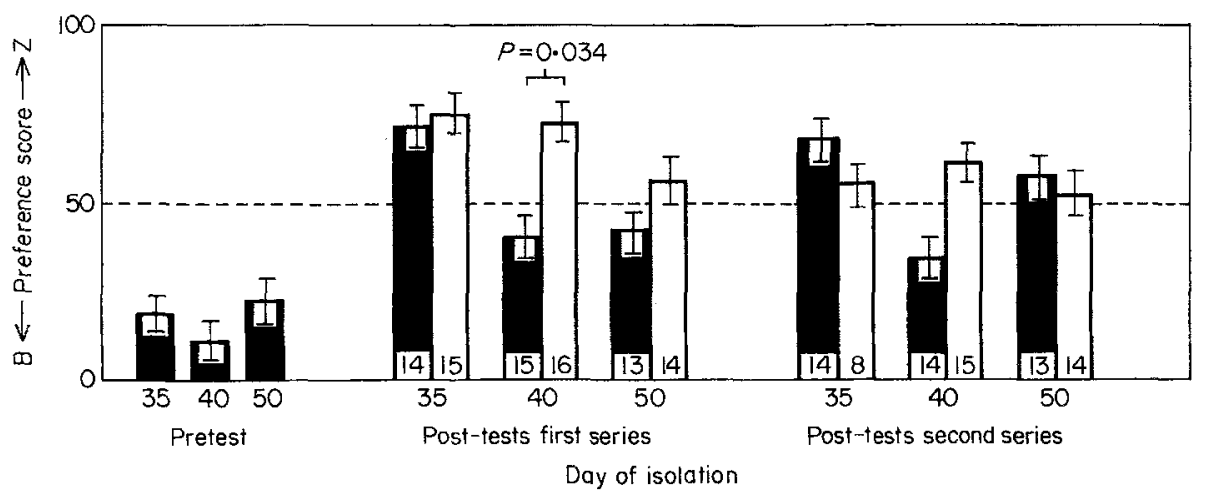

Figure 2. Preference scores (mean $\pm \mathrm{SE}$ ) of the different age groups in the pretests, and the first and second series of posttests, respectively. Number of birds indicated in each column. Significant differences are indicated. $\square$ : with pretest; $\square$ : without pretest.

respectively, were taken for further calculations. Differences between groups were tested with the Kruskal-Wallis $H$-test with a correction for tied ranks. The origin of the differences was then evaluated with Mann-Whitney $U$-tests.

In addition the data were processed in a different way which deviates from the above-described 'classical' calculation but shows better the individual differences of the birds involved in the study. For these calculations the preference of each bird was determined by a binomial test (Siegel 1976), which tested the probability of a difference between the amount of song directed to zebra finch females and that directed to Bengalese finch females, respectively. If this test showed a $95 \%$ probability of preference for one of the two choice objects, the bird was scored as having a preference for this object, otherwise it was scored as having no preference. The data obtained from this test (number of birds preferring one or other species or having no preference) were then compared by a chi-squared test or Fisher's exact test depending on the number of values in each class. For this purpose the birds preferring zebra finches were lumped together with the 'no preference' birds and the difference to those preferring Bengalese finches was tested.

All tests except the binomial test were performed by the statjstical package 'WiSTat' on an Atari Mega ST 4.

\section{RESULTS}

\section{Pretests}

All birds tested in the pretests strongly preferred females of the foster species, irrespective of the length of separation from their foster parents (Fig. 2 , pretest). The mean \pm SE preference scores (PS) were $18.43 \pm 5.05$ for the day 35 group $(N=14)$, $11.01 \pm 5.22$ for the day 40 group $(N=15)$ and $22.55 \pm 5.80$ for the day 50 group $(N=13)$. The differences between the groups were not significant (Kruskal-Wallis $H$-test and Mann-Whitney $U$-tests, $P$ estimated by a chi-squared distribution with $d f=5$ ).

The binomial tests also showed that the majority of the birds in all three age groups preferred Bengalese finches. In the day 35 group, 10 of 13 birds preferred Bengalese finches, two preferred zebra finches and one was undecided. In the 40-day group, 12 preferred Bengalese finches, one preferred zebra finches and two were undecided, and in the day 50 group seven preferred Bengalese finches, one preferred zebra finches and one was undecided (Fig. 3).

Group sizes used for the $H$-test and the binomial test differ because the binomial test gives unreliable results if the number of events is too small. We therefore excluded from these calculations all birds that reacted fewer than five times.

\section{Post-tests}

There were substantial differences between pretests and the first series of post-tests (Figs 2 and 3). The preference scores were significantly more zebrafinch directed in the post-tests of the day 35 and day 40 groups ( $U$-test, 35 days: $z=3 \cdot 703, P=0.001,40$ days: $z=2.971, P=0.013$ ). The same, but not significant, trend could be seen in the day 50 group $(z=1 \cdot 340, \mathrm{NS})$. 

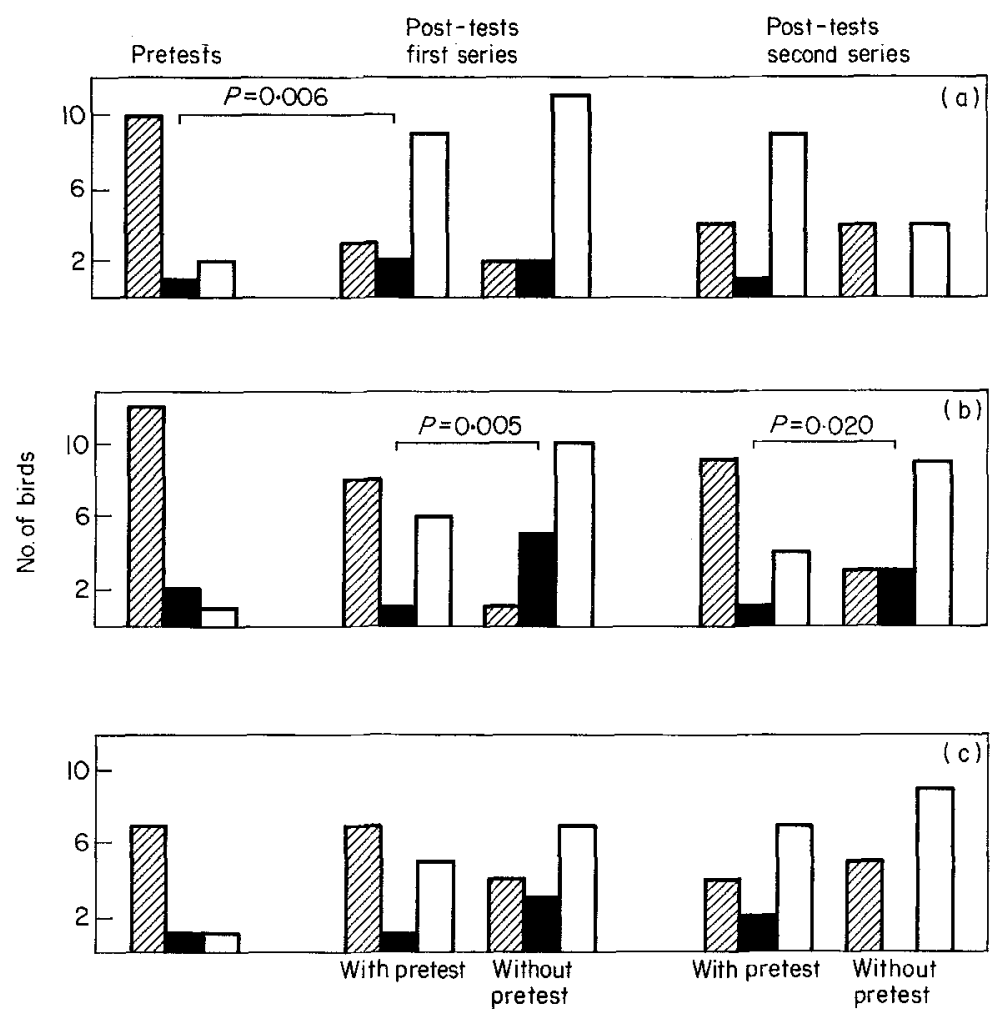

Figure 3. Number of birds in the different groups that had a preference for Bengalese finches preference $\square$. Classification according to a binominal test $(P \leqslant 0.05)$. Significant differences are indicated. (a) Day 35 group; (b) day 40 group; (c) day 50 group.

Between the different age groups, the results of the first post-test were not homogeneous ( $H$-test, $H=13.764, P=0.0171$, Fig. 2). All birds isolated at 35 days preferred their own species. There was no significant difference in the preference scores of birds with and without a pretest, respectively $\bar{X} \pm \mathrm{SE}=75 \cdot 11 \pm 5 \cdot 37$ without, $71 \cdot 15 \pm 5 \cdot 52$ with pretest; $z=0 \cdot 175$, Ns). In contrast, in the day 40 isolation group birds that had been given pretests differed significantly from those that had not ( $U$ test, $z=2.530, \quad P<0 \cdot 01)$. Birds that had not been given pretests preferred zebra finches ( $P S=$ $72 \cdot 81 \pm 5 \cdot 36$ ), whereas the group of birds with a pretest retained on average their original preference for the foster species (PS $=40 \cdot 56 \pm 5 \cdot 91$ ). The same, but not significant, tendency can be seen in the day 50 isolation group $(z=0.971, P=0.663)$ : for birds without pretests $P S=56 \cdot 40 \pm 5 \cdot 91$, whereas for those with pretests $P S=42 \cdot 32 \pm 5 \cdot 87$.

The calculations based on the binomial tests showed similar results (Fig. 3). In the day 40 group more birds with pretests preferred Bengalese finches than birds without a pretest $\left(\chi^{2}=8.330, P=0.005\right)$. The same, but not significant, tendency could be observed in the day 35 and day 50 groups.

\section{Stability of Preferences}

A second series of double-choice tests was performed 7-12 months later on the majority of the birds. The results are very similar to those of the first post-test although a non-significant trend can be seen in the day 35 and day 40 groups for a shift in preference towards a Bengalese score (Fig. 2). Whereas the preference scores for the day 35 and the day 50 groups differed between the pretests and the second post-tests ( $U$-tests, 35 days: $z=3.343$, $P=0.004,40$ days: $z=2 \cdot 329, P=0.086,50$ days: $z=2 \cdot 607, P=0 \cdot 04$ ), there were no significant differences between the first and the second post-test for either age group ( $H$-test and Fisher's exact test on the binomial data, respectively). This shows that the preferences that were already expressed in the 
first post-test series remained stable up to the second series of post-tests.

As in the first post-test series, the difference between birds with and without a pretest was significant only for the 40-day group (binomial test: $\chi^{2}=5.855, P=0.020$ ). The majority of the pretested birds of this age group retained their Bengalese finch preference, whereas the majority of the birds without a pretest preferred zebra finches (Fig. 3).

\section{DISCUSSION}

Our results demonstrate clearly that under certain circumstances a zebra finch male's preference for the foster species can be changed after 100 days of age. Furthermore it is possible to suppress substantially this change by a relatively short $(2 \times 20 \mathrm{~min})$ exposure to the foster-species even if the birds are presented with a female of their own species at the same time. Almost identical results have been obtained by Kruijt \& Meeuwissen (1991). Our findings are contrary to earlier concepts of imprinting (e.g. Immelmann \& Suomi 1981) which state that learning occurs only during a relatively short sensitive phase, the learned features being stable thereafter and not affected by further experience in adult birds.

Since the group without a pretest should have had the same preference for their foster parents as the group that was pretested, we can conclude that preferences were substantially changed after 7 months of breeding experience. The longer the birds were in contact with their foster parents, the less the preference changed. This is very similar to the results of Immelmann (1972, 1985; Immelmann \& Suomi 1981) that in experiments where the foster parents were replaced after a certain time by conspecific birds, a change from the initial preference for the foster parents to a preference for their own species depended on the age of transfer and how long the birds spent with the second species. The longer the birds were exposed to the first species, the less the final preference could be influenced by the second exposure. The longer the second exposure lasted, the more it affected the initial preference.

The longest time of exposure to the second species in Immelmann's experiments was 60 days. In our experiment the second experience (breeding with a conspecific female) started later, but lasted for 7 months. Therefore, with regard to the age of transfer, one could interpret this part of our data as extending Immelmann's findings to older birds and longer exposure time.

Such a result casts doubts on the original notion of a sensitive period for imprinting, as it shows that preferences can be altered even in adult birds, provided the second time of exposure is long enough. In the day 40 group, we did not find a significant reduction in preference in the five post-tests, but there was a small shift towards a Bengalese preference score after about 1 year. This means that the new preference, although not fully stable, is dominant over the first for more than 1 year even if there is some different experience in between. In contrast to these findings, Immelmann demonstrated in another series of experiments $(1972,1985$; Immelmann \& Suomi 1981) that cross-fostered males, which were isolated after day 40 and were exposed from day 100 to a zebra finch female for 7 months, exhibited a strong preference for the foster species and did not change the preference for their own species. Our results demonstrate that one reason for this difference in outcome may be the double-choice test that Immelmann routinely performed preceding the breeding experience with conspecifics. At least in the day 40 isolation group (the isolation time Immelmann preferentially used in his experiments) this double-choice test suppresses switches in preference of the male birds, even with long exposure to conspecific females. Moreover, we cannot exclude the possibility that Immelmann in his previous experiments selected only birds that showed an exclusive preference for the foster parents during the pretests.

One of us (Bischof 1979) has proposed that a preference obtained in early development is probably not stable until the birds could verify by courting whether the image learned in early development is adequate as a subject for courtship behaviour. This process of verification may consolidate the stored information and prevent it from further change. If the information cannot be verified in the first courtship encounter, as is the case in the group without pretests (here females of the foster species were not present), it can be at least partly replaced by new information derived from the first sexual partner even in adult birds.

This view is very similar to that developed for song learning. In the sensory phase of song learning a 'template' is acquired by the young bird, which later has to be matched with the individual's own song in the course of a so-called motor phase (e.g. 
Konishi \& Nottebohm 1969). For zebra finches,-a two-stage process in song learning was claimed by Böhner (1990) on the basis of his results on song acquisition. The sensory phase of song learning may therefore be comparable to the sensitive phase for imprinting, as it was originally defined, and the motor phase could be compared with the act of consolidation we demonstrate here.

The features of the process of consolidation are remarkable. First, the influence of the familiar species in the double-choice tests was much more effective than that of the unfamiliar species, even though this was a conspecific bird. Focusing on familiar individuals has been found in many aspects of behavioural development, e.g. in filial imprinting (Bateson 1980), for the gaping responses of young zebra finches (Bischof \& Lassek 1985) and song learning (Böhner 1983; Clayton 1987). Second, the time needed for consolidation was extremely short $(2 \times 20 \mathrm{~min})$. The ease with which information was acquired in spite of the short exposure time may be due to the bird's extremely high arousal level during this first courtship event, which facilitates the storage of information (e.g. Bateson 1983; Bischof 1983, 1985a, b). Bischof \& Hermann (1986, 1988) have indeed demonstrated that the activity of certain brain areas indicating arousal is very high after isolation and especially for males that see and court a female for the first time in their life, having been isolated from day 35 to day 100 , similar to our experiments. These two factors, namely focusing attention on the familiar bird and high general arousal, may be why such short exposure time has such drastic effects.

One has to consider here, however, that in our experiments the birds were isolated for a substantial time of their development, which may have raised the level of arousal to quite unnatural heights. Under normal conditions it is much more likely that the consolidation of sexual preferences occurs more gradually over a long period of interaction with conspecific females (which may also be the siblings) during the time of development.

Other aspects of our study are quite difficult to explain. For example, the consolidation effect is significant only in the day 40 isolation group. The day 35 group acquired an own-species preference after breeding experience irrespective of having a pretest or not. The easiest explanation would be that during their nestling phase these birds did not get enough information to consolidate in the pretests; however, the Bengalese finch preference of this group during the pretests was as strong as that of the other age groups. The consolidation effect in the day 50 isolation group was similar to the day 40 group, but was not significant. Probably, some of the birds older than 40 days may have had some sort of courtship experience with their siblings (which were zebra finches) and so may already have consolidated a certain preference for their own species at that time. As we did not control for this parameter, we cannot yet explain these data.

At least one other issue has to be discussed which leads to further complications. If one looks at the preferences of the individual birds (Fig. 3), one can see that the majority of the male zebra finches were not undecided (as Fig. 2 might suggest) but showed clear preferences for one of the species. Some of the birds retained their old preference for the foster species, others clearly preferred zebra finches. Probably, subtle differences in rearing conditions may be responsible for this outcome. These may be, for example, differences in interaction with the parents (feeding, aggression, Kruijt 1985; ten Cate 1986) or siblings (social or sexual interactions, Kruijt 1985; ten Cate 1986), or the state of development (e.g. hormones, Pröve 1985). Other reasons may be the different reactions of the choice females during the pretest, or those of the female during the breeding period. Our results provide only the first hint of which factors might influence the development of zebra finch male sexual preferences.

To conclude, our results show that the mechanisms underlying sexual imprinting may be much more complicated than previously believed. The fact that the information learned in early development has to be verified in a sexual context suggests that sexual imprinting may be very similar to song learning, but less similar to recent ideas of filial imprinting. However, further research may uncover such a consolidation effect, which can be claimed at least theoretically (Bischof 1979) for both sexual and filial imprinting. Indeed a two-stage process may be a common feature of imprinting and other imprinting-like processes.

\section{ACKNOWLEDGMENTS}

The experiments described here were initiated and planned by Professor Klaus Immelmann and performed mainly by Ragna Pröve. Both of them died before the assessment of the results was finished. We hope we have interpreted their data as they 
would have wished. Our thanks are due to J. Kruijt, N. Clayton and J. Böhner for valuable comments; to N. Clayton for help in improving the English text and giving statistical advice; and to E. Geißler, who drew the figures and typed the manuscript. The study was supported by the Deutsche Forschungsgemeinschaft $(\operatorname{Im} / 18-1$, Bi245/5-1).

\section{REFERENCES}

Bateson, P. P. G. 1980. Rules and reciprocity in behavioural development. In: Growing Points in Ethology (Ed. by P. P. G. Bateson \& R. Hinde), pp. 401-421. Cambridge: Cambridge University Press.

Bateson, P. P. G. 1981. The control of sensitivity to the environment during development. In: Behavioural Development. The Bielefeld Interdisciplinary Project (Ed. by K. Immelmann, G. W. Barlow, L. Petrinovich \& M. Main), pp. 432-453. Cambridge: Cambridge University Press.

Bateson, P. P. G. 1983. The interpretation of sensitive phases. In: The Behavior of Human Infants (Ed. by A. Oliverio \& M. Zappella), pp. 57-70. New York: Plenum Press.

Bischof, H.-J. 1979. A model of imprinting evolved from neurophysiological concepts. Z. Tierpsychol., 51, 126-139.

Bischof, H.-J. 1983. Imprinting and cortical plasticity: a comparative review. Neurosci. Biobehav. Rev., 7, 213-225.

Bischof, H.-J. 1985a. Environmental influences on early development: a comparison of imprinting and cortical plasticity. In: Perspectives of Ethology. Vol. 6: Mechanisms (Ed. by P. Bateson \& P. Klopfer), pp. 169-217. New York: Plenum Press.

Bischof, H.-J. 1985b. Influence of developmental factors on imprinting. In: Brain Plasticity, Learning, and Memory: Advances in Behavioral Biology 28 (Ed. by B. E. Will, P. Schmitt \& J. Dalrymple-Alford), pp. 51-59. New York: Plenum Press.

Bischof, H.-J. \& Hermann, K. 1986. Arousal enhances 14-C-2 deoxyglucose uptake in four forebrain areas of the zebra finch. Behav. Brain Res., 21, 215-221.

Bischof, H.-J. \& Hermann, K. 1988. Isolation-dependent enhancement of $2-\left({ }^{14} \mathrm{C}\right)$-deoxyglucose uptake in the forebrain of zebra finch males. Behav. neural Biol., 49, 386-397.

Bischof, H.-J. \& Lassek, R. 1985. The gaping reaction and the development of fear in young zebra finches
(Taeniopygia guttata castanotis). Z. Tierpsychol., 69, 55-65.

Böhner, J. 1983. Song learning in the zebra finch (Taeniopygia guttata): selectivity in the choice of a tutor and accuracy of song copies. Anim. Behav., 31, 231-237.

Böhner, J. 1990. Early acquisition of song in the zebra finch, Taeniopygia guttata. Anim. Behav., 39, 369-374.

Clayton, N. S. 1987. Song tutor choice in zebra finches. Anim. Behav., 35, 714-721.

Immelmann, K. 1959. Experimentelle Untersuchungen über die biologische Bedeutung artspezifischer Merkmale beim Zebrafinken (Taeniopygia guttata castauotis). Zool. Jb., 86, 438-593.

Immelmann, K. 1972. The influence of early experience upon the development of social behaviour in estrildine finches. Proc. int ornithol. Congr., 15, 316-338.

Immelmann, K. 1985. Sexual imprinting in zebra finches: mechanisms and biological significance, Proc. int. ornithol. Congr., 18, 156-172.

Immelmann, K. \& Suomi, S. J. 1981. Sensitive phases in development. In: Behavioral Development. The Bielefeld Interdisciplinary Project (Ed. by K. Immelmann, G. W. Barlow, L. Petrinovich \& M. Main), pp. 395-431. Cambridge: Cambridge University Press.

Konishi, M.\& Nottebohm, F. 1969. Experimental studies in the ontogeny of avian vocalizations. In: Bird Vocal izations (Ed. by R. A. Hinde), pp. 29-48. New York: Cambridge University Press.

Kruijt, J. P. 1985. On the development of social attachment in birds. Neth. J. Zool., 35, 45-62.

Kruiit, J. P. \& Meeuwissen, G. B. 1991. Sexual preferences of male zebra finches: effects of early and adult experience. Anim. Behav., 42,91-102.

Kruijt, J. P., ten Cate, C. J. \& Meeuwissen, G. B. 1983. The influence of siblings on the development of sexual preferences of male zebra finches. Devl Psychobiol. 16, 233-239.

Pröve, E. 1985. Steroid hormones as a physiological basis of sexual imprinting in male zebra finches. In: The Endocrine System and the Environment (Ed. by K. B. Follett, S. Ishii \& A. Chandola), pp. 235-245. Berlin: Springer-Verlag.

Siegel, S. 1976. Nichtparametrische statistische Methoden. Frankfurt/M: Fachbuchhandlung Psychologie, Verlagsabteilung.

ten Cate, C. 1985. Directed song of male zebra finches as a predictor of subsequent intra- and interspecific social behaviour and pair formation. Behav. Proc., 10, 369-374.

ten Cate, C. 1986. Sexual preference in zebra finch (Taeniopygia guttata) males raised by two species (Lonchura striata and Taeniopygia guttata). I. A case of double imprinting. J. comp. Psychol., 100, 248-252. 